\title{
BAGAIMANA CARA MENJALANI PERAN KEPALA SEKOLAH?
}

\section{Nur Afifatus Solicha}

Universitas Nahdlatul Ulama Sidoarjo

\section{LATAR BELAKANG}

Saya menulis daftar kiat ini untuk mengilhami, menantang, dan mengembangkan pemimpin sekolah atau pemilik sekolah atau wirausahawan pendidikan yang efektif. Saya melakukan ini dengan membuat konten yang konsisten sepanjang minggu melalui blog. Saya juga sedang mengerjakan podcast yang akan mewawancarai kepala sekolah dan wirausahawan sekolah yang sangat efektif untuk berbagi strategi dan kebijaksanaan yang telah mereka pelajari melalui pengalaman dan kesalahan. Orang suka membaca daftar. Terutama daftar "tips" yang dapat membantu seseorang mempercepat pemahaman mereka tentang suatu topik. Saya pikir itu akan menjadi tantangan besar untuk menulis daftar lengkap kiat untuk kepala sekolah. Tulisan ini akan 
memberikan beberapa tips bagi anda sang kepala sekolah dan wirausahawan pendidikan.

\section{KOMPROMI}

Pemimpin sekolah sebisanya tegas, toleran terhadap bawahannya dan mengayomi. Pendidikan adalah catatan masa lalu dan pengajaran masa kini untuk masa depan bangsa. Pendidikan adalah menyampaikan ilmu dan mentransformasi orang lain menjadi lebih baik (Fidiana et al., 2017). Di taman siswa-siswa Anda belajar bahwa Anda tidak selalu bisa melakukannya sendiri. Ingat bahwa "bos" hanyalah sebuah gelar. Itu tidak berarti Anda harus menuruti keinginan Anda (Bauer, 2019).

\section{PENGALAMAN WIRAUSAHA}

Menjaga hubungan baik dengan wali siswa melalui melaksanakan janji dan pelayanan yang baik adalah bagian dari promosi wirausaha (Asitah, Usmawati, Rosyidah, \& Purnomo, 2017). Toleransi, bekerja sama, bertanggungjawab, dan amanah adalah prinsip wirausaha pendidikan (Nahdiyah, Amrina, Purnomo, \& Rosyidah, 2017). Edupreneur atau educational entrepreneur berasal dari dua kata yaitu education bermakna pendidikan dan entrepreneur bermakna pengusaha atau wirausahawan. Ada juga yang 
menyamakan istilah edupreneur dengan istilah teacherpreneur (Purnomo, 2017).

\section{SPRITUAL SPIRIT}

Hubungan pendidikan antara guru dan murid itu seperti aliran listrik dengan lampu. Bagaimana lampu itu bisa menyala kalau aliran listriknya juga mati ?. Bagaimana murid itu bisa berprestasi sedangkan guru sendiri tidak pernah berprestasi dan mendoakan (Fidiana, Istiana, Rosyidah, \& Purnomo, 2017). Pendidikan adalah kunci untuk membuka pintu emas kesuksesan. Wirausaha pendidikan dengan motivasi bisnis dengan Allah Ta'ala sebagai bentuk kenyamanan untuk ibadah. Tips mengelola institusi pendidikan adalah niat mendidik dan berjuang karena Allah ta'ala. Niscaya rintangan sebesar apapun akan terasa ringan dihadapan kita. Melihat anak mengenal Allah Ta'ala dan sukses akhlak dan pengetahuannya merupakan kebahagiaan pendidik (Yuniarti, Kautsari, Sholichah, Purnomo, \& Rosyidah, 2017). Setiap manusia hamba Tuhan yang memiliki ilmu selayaknya harus mengamalkan ilmu tersebut (Asitah et al., 2017). Prinsip pendidikan adalah sosial. Sebagai seorang guru, kita harus memiliki kepedulian sosial (Asitah et al., 2017). Guru harus bisa membangun generasi muda untuk masa depan. 
Hiduplah untuk mengamalkan ilmu (Sholichah, Istiqomah, Rosyidah, \& Purnomo, 2017).

\section{MENGELOLA WAKTU ANDA}

Manajemen sekolah dilakukan dengan menerapkan standar kualitas dalam rekrutmen pengajar yaitu kedekatannya dengan amaliyah (Munjidah, Zannah, Purnomo, \& Rosyidah, 2017). Panduan ini menawarkan beberapa saran untuk membantu Anda mengatur waktu Anda sendiri dan agenda waktu lainnya (Educational Leaders, 2019).

\section{HORMATI ORANG LAIN SEBELUM VISI ANDA}

Visi yang inspiratif dapat mendorong staf untuk memindahkan organisasi ke tingkat kesuksesan yang belum pernah terjadi sebelumnya. Namun, pemimpin sekolah yang baik tidak akan pernah menjadi hebat dan mencapai visinya jika dia menempatkan visi di depan orang-orangnya (Bauer, 2019).

\section{CIRI KEPALA SEKOLAH EFEKTIF}

Kepala sekolah yang efektif

berkomunikasi, berkomunikasi, berkomunikasi, menghormati dan menghargai keanekaragaman dan mengelola konflik secara kreatif dan tepat waktu (Harris, 2019). Kesabaran dan komunikasi 
yang baik dengan masyarakat sekitar adalah kunci untuk dapat mengatasi masalah dan bisa bangkit dari keterpurukan manajemen pendidikan. Prinsip utama dan kepemimpinan wirausaha pendidikan adalah disiplin, kreatif, cerdas dan ulet (Qori'ah et al., 2017).

\section{BERPIKIR DI LUAR KOTAK}

Jangan pernah membatasi diri Anda dan guru Anda. Berakal dan temukan cara kreatif untuk memenuhi kebutuhan ketika masalah muncul. Jangan takut untuk berpikir di luar kotak.

Dorong guru Anda untuk melakukan hal yang sama. Kepala sekolah yang sukses adalah pemecah masalah elit. Jawaban tidak selalu mudah. Anda harus memanfaatkan sumber daya secara kreatif yang Anda miliki atau mencari cara untuk mendapatkan sumber daya baru untuk memenuhi kebutuhan Anda. Pemecah masalah hebat tidak pernah menolak ide atau saran orang lain. Sebaliknya, mereka mencari dan menghargai masukan dari orang lain secara kooperatif menciptakan solusi untuk masalah (Meador, 2019). Tips kelola sekolah adalah senantiasa belajar dan bekerja keras. Bersabarlah dengan masalah, sesungguhnya didalam kesulitan ada kemudahan (Sholichah et al., 2017). 


\section{MENAKAR PENDIDIKAN}

Hasil penelitian menunjukkan bahwa penerapan pembelajaran dapat meningkatkan prestasi siswa; dan tes menunjukkan bahwa prestasi belajar siswa kelas belajar lebih baik daripada siswa kelas konvensional (Iskandar, Rizal, Kurniasih, Sutiksno, \& Purnomo, 2018). Pendidikan itu sebuah perhiasan dalam kemakmuran dan tempat bernaung dalam kesengsaraan (Maula, Mufidah, Rosyidah, \& Purnomo, 2017). Cari ilmu yang bermanfaat dan patuhi aturan-aturan yang ada. Bijaksana dan pantang menyerah dalam belajar adalah kunci kesuksesan. Pendidikan adalah pelajaran yang harus kita pelajari setiap hari baik dari buku, lingkungan, teman, maupun keluarga agar kita tidak tertinggal (Qori'ah, Sholichah, Purnomo, \& Rosyidah, 2017). Guru merupakan seorang yag memilki tugas mulia sebagai pendidik dan pengajar sekaligus sebagai pembentuk kepribadian siswa (Maula et al., 2018).

\section{MEMILIKI PROSEDUR KONTROL YANG BAIK}

Beberapa prosedur pengendalian yang baik dikembangkan untuk mencegah masalah. Sebagai contoh, lembar sampul dapat membantu mencegah siswa-siswa menyontek saat ujian tertulis. Prosedur tersebut harus semudah 
mungkin bagi siswa untuk memilih hal yang benar dan sesulit mungkin bagi mereka untuk berperilaku tidak pantas atau mengambil keputusan yang tidak sempurna (Edsys, 2016).

\section{BERMITRA DENGAN PENELITI}

Di sekitar Anda akan melihat universitas dan perguruan tinggi mencoba yang terbaik untuk menghasilkan pelajaran kelas yang inovatif. Mereka selalu berusaha mencari tahu kualitas teknologi pendidikan baru, dan menghasilkan praktik pengajaran yang terbukti efektif bagi mereka. Sebagai contoh, di universitasuniversitas tertentu para peneliti mencari cara di mana sastra siswa-siswa, yang sangat interaktif dan visual, dapat membantu meningkatkan keterampilan menulis dan membaca para siswa. Sebagai hasil dari penelitian guru seperti di kelas ini sekarang mendapatkan rencana pelajaran, ide, dan bahan yang dapat mereka gunakan untuk tahun-tahun mendatang (Fedena, 2018).

\section{DO, DELEGATE, ATAU DUMP}

Saat mengatur barang-barang, beberapa orang membuat tumpukan, menyumbang, atau membuang sampah. Tidak ada bedanya dengan kehidupan kerja Anda. Mengelompokkan tugas ke dalam do, delegate, atau dump akan 
menghemat waktu dan sakit kepala Anda. Disebut sebagai $3 \mathrm{D}$, alat manajemen waktu ini adalah penyelamat hidup. Mengacu pada tugastugas yang perlu Anda selesaikan sendiri dan mungkin perlu diprioritaskan. Delegasi mencakup semua tugas yang dapat dilakukan oleh orang lain di tim Anda. Sekarang ini tidak berarti menyerahkan tugas karena Anda benci melakukannya. Maksudnya adalah mempercayai tim Anda untuk menyelesaikan tugas-tugas penting yang Anda hadapi (Kerns, 2016).

\section{INGAT TUJUAN AKHIR ANDA}

Tidak peduli siapa Anda atau apa yang Anda lakukan, Anda akan bertemu dengan siswa yang menantang Anda. Saat bekerja dengan siswa yang menantang, Anda mungkin perlu berkompromi. Saat melakukannya, tanyakan pada diri sendiri, "Apa tujuan akhirnya?". Setelah Anda jelas pada tujuan akhir, cari tahu hal-hal apa yang penting serta beberapa bidang untuk kompromi (Kane, 2018).

\section{BUJUK ORANG TUA YANG MARAH UNTUK BERBICARA DENGAN GURU TERLEBIH DAHULU}

Cara memimpin sekolah adalah senantiasa musyawarah serta sharing bersama 
para guru atau dengan siapapun dan tetap mendekat pada Allah SWT (Yuniarti et al., 2017). Jika masalah tidak terselesaikan setelah berbicara dengan guru; minta mereka menghubungi Anda untuk membantu memperbaiki situasi (Drewitt, 2017).

\section{KOLABORASI EKSEKUTIF}

Di bulan pertama Anda, berkolaborasi dengan tim eksekutif Anda untuk membuat rencana aksi satu tahun berdasarkan rencana strategis sekolah. Rencsiswaan ulasan 90 hari, rayakan keberhasilan Anda dan jadwalkan kembali tujuantujuan yang tidak tercapai. Tidak apa-apa untuk menjadi gesit dan fleksibel selama Anda fokus pada apa yang paling penting (Driscoll, 2018).

\section{JANGAN MENGIRA GURU MENGINGINKAN ANDA SEBAGAI TEMAN MEREKA}

Siswa perlu memahami apa yang diketahui dan apa yang diminta untuk memiliki kemampuan menjawab (Suci et al., 2018). Mereka membutuhkan seseorang yang akan memastikan sekolah berjalan dengan baik (Drewitt, 2017). 


\section{MEMAHAMI PEKERJAAN SEKOLAH}

Panduan ini memiliki informasi tentang menunjuk staf, penggajian, persetujuan, dan kinerja (Educational Leaders, 2019). Pemimpin sekolah dan wirausaha pendidikan seharusnya senantiasa menikmati proses karena tidak ada hal yang besar yang tidak dilakukan dari hal yang kecil. Semua butuh proses, karena kesuksesan tidak datang secara langsung tanpa berproses (Maula et al., 2017).

\section{TULIS CATATAN PENGHARGAAN}

Jangan pernah meremehkan tindakan sederhana berterima kasih kepada staf Anda karena telah melakukan pekerjaan dengan baik (Drewitt, 2017). Guru merupakan seorang pendidik dan pengajar sekaligus sebagai pembentuk kepribadian siswa yang unggul, berwawasan dan baik (Maula et al., 2018).

\section{BERKOMUNIKASI SECARA EFEKTIF}

Merumuskan visi tidak memadai jika tidak dikomunikasikan dengan baik. Pernyataan visi kepala sekolah (atau pengawas sekolah atau dewan sekolah) harus dikomunikasikan kepada semua orang yang terkena dampak visi, termasuk guru, siswa, dan orang tua. Itu berarti memperbarui guru, siswa, dan orang tua secara 
teratur tentang kemajuan pernyataan visi dan langkah-langkah yang diperlukan untuk mencapainya. Selain itu, pemimpin yang efektif memprioritaskan pengembalian email, panggilan telepon, dan teks sesegera mungkin atas dokumen dan tanggung jawab administratif lainnya yang tidak memiliki tenggat waktu yang mendesak (Watanabe-Crockett, 2018).

\section{MULAI DI SEKOLAH BARU}

Pendidikan Indonesia membutuhkan peningkatan akses, mutu dan relevansi pendidikan untuk memberi manfaat membangun bagi pendidikan dan rakyat Indonesia (Irawan et al., 2018). Panduan ini memiliki saran untuk membantu menjadikan istilah pertama positif, menghindari masalah besar dan mengembangkan proses yang baik (Educational Leaders, 2019). 


\section{REFERENCES}

Asitah, N., Usmawati, D. Z., Rosyidah, E., \&

Purnomo, A. (2017). MI Hasyim Asy'ari Ilmu

Harus Terus Mengarus. In Wirausaha

Pendidikan Indonesia (Jilid 2). Sidoarjo:

UNUSIDA Press.

Bauer, D. (2019). 200 Tips for Effective School

Leaders. Retrieved June 11, 2019, from https://www.betterleadersbetterschools.com/ 200-tips-effective-school-leaders/

Communicator. (2017). 4 Time Management

Tips for Principals. National Association of

Elementary School Principals, 40. Retrieved from https://www.naesp.org/communicatorjune-2017/4-time-management-tips-

principals

Covey, S. (1996). First things first. New York:

Simon and Schuster.

Drewitt, P. (2017). 25 tips for School Principals.

Retrieved June 10, 2019, from

https://www.linkedin.com/pulse/25-tips-

school-principals-paul-drewitt

Driscoll, M. (2018). 16 Success Tips for New

21st Century Principals. Retrieved June 23,

2019, from

https://thinkstrategicforschools.com/16-

success-tips-new-21st-century-principals/ 
Edsys. (2016). 10 Awesome Tips to Manage School Discipline Issues. Retrieved June 27, 2019, from https://www.edsys.in/10awesome-tips-to-manage-school-disciplineissues/

Educational Leaders. (2019). Guides for managing your school. Retrieved June 28, 2019, from

http://www.educationalleaders.govt.nz/Mana ging-your-school/Guides-for-managing-yourschool

Fedena. (2018). Quality tips for better school management. Retrieved June 24, 2019, from

https://fedena.com/blog/2018/11/quality-tipsfor-better-school-management.html Fidiana, W., Istiana, Z., Rosyidah, E., \&

Purnomo, A. (2017). MINU Waru 2 Insan Berkilau Cahaya Manfaat. In Wirausaha Pendidikan Indonesia (Jilid 4). Sidoarjo: UNUSIDA Press.

Harris, S. (2019). 10 Survival Tips for New, Struggling School Principals. Retrieved June 21, 2019, from

https://www.teachhub.com/10-survival-tipsfor-school-principals Irawan, D. E., Purnomo, A., Sutiksno, D. U., Abraham, J., Alamsyah, A., Saputra, D. H., ... Rosyidah, E. (2018). Kajian Pendidikan Tinggi IDRI untuk DPR RI dan Ristek Dikti 2018. Bandung: ITB Press. 
Iskandar, A., Rizal, M., Kurniasih, N., Sutiksno, D. U., \& Purnomo, A. (2018). The Effects of Multimedia Learning on Students Achievement in Terms of Cognitive Test Results. Journal of Physics: Conference Series, 1114(1), 012019. https://doi.org/10.1088/17426596/1114/1/012019

Kane, A. (2018). 5 Essential Tips for Managing High School Students. Retrieved June 23, 2019, from

https://theartofeducation.edu/2018/07/02/5essential-tips-for-managing-high-schoolstudents/

Kerns, K. (2016). 5 Time Management Tips for School Administrators. Retrieved June 26, 2019, from http://help.thesubservice.com/blog/5-timemanagement-tips-for-school-administrators Maula, I., Asitah, N., Munjidah, A., Nahdiyah, K., Yuniarti, D., Sholichah, S. A., ... Qori'ah, S. (2018). Kontribusi Kreativitas Guru SD dalam Induksi Pembelajaran.

https://doi.org/http://doi.org/10.17605/OSF.I O/BS795

Maula, I., Mufidah, F. I., Rosyidah, E., \& Purnomo, A. (2017). SD Antawirya Islamic Javanese School Mother is Culture. In Wirausaha Pendidikan Indonesia (Jilid 1). Sidoarjo: UNUSIDA Press. 
Meador, D. (2019). 10 Things a Successful School Principal Does Differently. Retrieved June 25, 2019, from

https://www.thoughtco.com/things-asuccessful-school-principal-does-differently3194532

Munjidah, A., Zannah, I. P. N., Purnomo, A., \&

Rosyidah, E. (2017). MI Thoriqussalam Berpegang Kepada Rosul. In Wirausaha Pendidikan Indonesia (Jilid 4). Sidoarjo: UNUSIDA Press.

Murray, J. (2018). Time Management Tips for School Leaders - Part I. Retrieved June 25, 2019, from

https://www.ccu.edu/blogs/cags/2018/01/tim e-management-tips-for-school-leaders-parti/

Nahdiyah, K., Amrina, S., Purnomo, A., \& Rosyidah, E. (2017). SD Taman Pendidikan Islam Porong Iman Kuat Bekal di Akhirat. In Wirausaha Pendidikan Indonesia (Jilid 2). Sidoarjo: UNUSIDA Press.

Okoli, A. (2017). 3 Little Changes that Would Make a Big Difference to your School Management. Retrieved June 29, 2019, from https://safsms.com/blog/3-changes-toimprove-school-management/ 
Peel District School Board. (2019). Becoming an Effective Youth Leader. Retrieved June 20, 2019, from

http://www.peelschools.org/students/student activitycouncil/tipsforbeingeffectiveschoollea der/Pages/default.aspx

Purnomo, A. (2017). Pengertian Edupreneur. https://doi.org/10.31227/osf.io/8fnu6 Qori'ah, S., Sholichah, S. A., Purnomo, A., \& Rosyidah, E. (2017). Progresif Bumi Sholawat dengan Kebenaran Semua Pasti Ada Jalan. In Wirausaha Pendidikan Indonesia (Jilid 3). Sidoarjo: UNUSIDA Press.

Sholichah, S. A., Istiqomah, A., Rosyidah, E., \& Purnomo, A. (2017). MI Darun Najah Berfikir Berkarya Berdzikir. In Wirausaha Pendidikan Indonesia (Jilid 3). Sidoarjo: UNUSIDA Press.

Springer. (2019). Tips for Managing Organization. Retrieved June 29, 2019, from https://www.springer-ld.org/springerexperience/center/parent-programs/tipsorganization

Suci, S. H. A., Rosyidah, E., Asitah, N., Aini, N., Murni, A. W., Anam, F., ... Kuraesin, A. D. (2018). Learning from Picture and Picture Action Research : Enhancement of Counting Ability on Division of Numbers for Primary School Students. Journal of Physics: Conference Series, 1114(1), 012044. https://doi.org/10.1088/1742- 
$6596 / 1114 / 1 / 012044$

Watanabe-Crockett, L. (2018). The 10 School

Leadership Best Practices That Make a

Difference. Retrieved June 20, 2019, from

https://www.wabisabilearning.com/blog/10-

school-leadership-best-practices

Yuniarti, D., Kautsari, M. F., Sholichah, F.,

Purnomo, A., \& Rosyidah, E. (2017). SMP

SMA Al-Amin Ponpes Bahrul Hidayah

Serahkan pada Allah Ta'ala. In Wirausaha

Pendidikan Indonesia (Jilid 1). Sidoarjo:

UNUSIDA Press. 